\title{
A Contrastive Analysis of English and Wolof Noun Phrases
}

\author{
Hafissatou KANE \\ Cheikh Anta DIOP University of Dakar (Senegal)
}

\begin{abstract}
This study aims at contrasting the Noun Phrase of English and Wolof. The constituents compared here are the noun head, the definite articles and possessive determiners to pinpoint similarities and differences between the two languages. In doing so, an inventory of Wolof and English simple noun phrases has been investigated using the contrastive method. Results present more differences than similarities between the two languages. English nouns have no morphological marks distinguishing masculine and feminine forms, a feature which also applies to their Wolof counterparts. Another similarity is, possessive determiners are placed before the head in both languages, except the bound possessive -am, suffixed to the noun in Wolof. Points of differences between the two languages occur as follows: the use of noun classes is typical to Wolof. Wolof nouns are invariable but characterized with noun classes that generally appear on determiners which bear number marking. Contrary to Wolof, English singular nouns are morphologically distinguished from plural nouns. Another difference between the two languages occurs with possessive determiners that agree in number with their heads in Wolof while they are invariable in English except with a variation between his / her / and its, a feature not expressed in Wolof. One of the main differences between the two languages is English has one invariable definite article 'the 'that always occupies the initial position of the noun phrase. Contrary to English, Wolof definite articles are placed after the heads. They are made of the noun class of the head and agree in number with the latter. They also express closeness and remoteness of the referred item, a criterion absent in English. Finally, another important distinction is, in English, a noun phrase cannot contain the definite article and possessive determiner at the same time while in Wolof, the presence of both determiners is accepted.
\end{abstract}

Key words: Contrastive study, noun phrase, English, Wolof

\section{Introduction}

Language is recognized as a very complex system. Each language is characterized by internal features that make it particular. It has been noticed that each language is composed of various and unique elements that are divided up in several ways. One category of these elements is the whole combination of sounds we produce when we communicate. Another category is the hierarchical structure in which sounds are grouped together into words and from words to phrases and the latter to sentences. However, the study of linguistic structures and grammatical systems always tells us how much our languages are similar or different from one another.

In this paper, I will analyse one constituent of both English and Wolof languages, which is the Noun Phrase. Since the analysis of the noun phrase can be very complex, the aim of this work is to investigate the simple Noun Phrase. The study does not either involve all the possible constituents of a noun phrase. It is rather limited to the relation between noun heads and two of its determiners: definite article and possessives both in English and Wolof noun phrases. The study attempts to achieve the following objectives:

- To discuss the three targeted constituents (noun, definite articles and possessives) in both English and Wolof noun phrases.

- To identify the similarities and differences in structures and other features.

\section{Literature review}

Contrastive analysis, is a branch of applied linguistics which compares the linguistic systems of two or more languages. This descriptive comparison shows how languages differ in their sound system, grammatical structure and vocabulary. These analyses have been recognized to be useful in areas like language teaching, translation, and designing syllabus etc. They are used to point out the areas where the similarities and discrepancies between two or more languages are present.

\subsection{Contrastive studies between English and other languages}

This literature review consists of three sections. It first discusses some studies contrasting several linguistic features of English and other languages. The second section focuses on linguistic works investigating the similarities and differences between Wolof and other languages. This literature review finally explains the main characteristics of a noun phrase. Revisiting the literature, there are several studies contrasting various aspects of languages with English. 
Jamal (2013) has done a research in English and Arabic and contrasted both languages in terms of noun morphology. He has discovered that both languages share common features as well as differences in the expression of gender, number, genitive case and personal pronouns.

Al Faki (2014)'s research focused on analysing and contrasting sentence construction in both Nubian and English languages. The findings reveal that English and Nubian languages have the following similarities. The two languages have similar elements to construct a sentence. Both languages use coordination to construct compound and complex sentences and have both equivalent conjunctions. English and Nubian language shave equivalent pronouns to construct $(W H)$ questions and one of their common features is that ellipsis exists in both languages. Yet the two languages have different syntactic order of elements in sentence construction. For instance, coordinators in English convey shades of meaning whereas in the Nubian language they cannot do so. Ellipsis, in the Nubian, does not result in an ambiguous sentence. The coordinator appears in the middle of the sentence. The presence of more than one coordinator may result in an ambiguous sentence. In Nubian languages, the coordinator appears after the nominal in each clause and no ambiguous sentence may result (Al Faki, 2014: 1).

In another contrastive analysis between the French noun phrase and the English noun phrase, Salim (1991: 35) has shown that the French noun phrase and the English noun phrase have both similarities and differences. Structurally, the French noun phrase is similar to its English counterpart. They both can contain the same elements and are always headed by the noun. The noun head does not present major differences between the two languages, except the notion of grammatical gender which is typical to French. With regards to the noun specifiers, few differences exist between the two languages and the same can be said for adjectives. However, in French, the adjectives are known to agree in gender and number with the noun they modify. He concludes that there are more similarities than differences between the French noun phrase and the English noun phrase.

\subsection{Contrastive studies between Wolof and other languages}

Many research works are conducted comparing Wolof and other languages through several linguistic features. For instance, in his contrastive study of affixation in English and Wolof, Mbaye (2013: 65) found that both Wolof and English are rich in terms of affixation. However, English uses a number of prefixes to express repetition, negation and negative forms while Wolof does not use prefixes. He also indicates that suffixation is mainly used in English to obtain adjectives from verbs and nouns but Wolof uses suffixation to express reduction.

Investigating the morphological and syntactic features of possessives in Wolof and English, Diagne (2013: 64), concludes that each language has its own particularities in the use of possessives. For instance, number does appear in English possessives while Wolof possessives do not agree in gender. The points of similarities are as follows: possessive adjectives play a role of determiners in both languages. The other thing they have in common is the use of clitics. Wolof uses the clitic "- $u$ " and English uses the clitic "s".

In the same line of interest, Ndione (2013) dealt with reduplication and repetition in French and Wolof in his doctoral thesis. The analysis showed that reduplication does not occur more in Wolof than in French, since similar reduplicated categories (nouns, adjectives, verbs etc.) can be found in both languages. In French, for example, one can reduplicate proper names (e.g. Dédé, Vava etc.), nouns (e.g. salade-salade), verbs (e.g. il pleut pleut), adjectives (e.g. joli-joli) and adverbs (e.g. loin-loin). In Wolof, one can reduplicate patronyms (e.g. wade-wade), toponyms (e.g. bawol-bawol), lexical tap roots (e.g. am-am 'possession'), adverbs (e.g. leeg-leeg 'often') and nouns (e.g. góor-góor-lu 'resourceful').Searching for relevant and reliable criteria in order to distinguish between reduplication and repetition both in French and Wolof, Ndione found that in Wolof, reduplication implies a lexical creation while repetition does not. He also found that repetition in Wolof can be identified thanks to the vowel "a" but not reduplication. Further, in French, reduplication can help to create nicknames but not repetition Ndione (2013: 5).

Indeed several research works have been done contrasting or comparing English and Wolof to other languages. In Senegal, many studies have also contrastively investigated different aspects of Wolof and English languages. As stated, this study focuses on the structural and other features that distinguish English and Wolof noun phrases. Knowing that English and Wolof are typologically two distinct languages, I predict that the comparison of their noun phrases will present more differences than similarities. However, I also believe that these expected similarities and differences will contribute to the understanding of the grammar of both languages. This understanding in turn, will be helpful in teaching and learning English and Wolof as second languages. Before starting the analysis and discussion of the data, it is necessary to recall the main characteristics of a noun phrase.

\subsection{The Noun Phrase}

A noun phrase is a phrase that contains and is centred on a noun, also called a head. In Payne (1997: 33), the head of a noun phrase is the one word within the phrase that refers to the same entity that the whole phrase refers to. For example, an English phrase like 'that computer man' refers to time-stable concept, so we suspect it is a noun phrase.

115 
However, it also contains two words that also refer to time-stable concepts, computer and man. So the question arises as to which of the two nouns is the head of the noun phrase. The answer in this case is easy: the whole phrase refers to a man, not a computer, therefore the noun man is the head of the noun phrase. The distinction between the head and the remaining elements of the noun phrase is that the head noun is obligatory. The other elements can be omitted. When we say that a noun phrase consists of a head noun and other secondary elements and that the secondary elements are typically optional, it automatically follows that a noun can consist just of a head noun. This has been observed in English and Wolof as well. In both languages a noun phrase may consist of single noun or a sequence of various elements headed by a noun.

Noun phrase elements include determiners, numerals, genitives (possessors), modifiers (attributive adjectives), relative clauses, noun classifiers, and the head noun. The noun head is the noun that is modified by all the other elements.

\section{Methodology}

In order to compare and contrast the Noun Phrase constituents of English and Wolof; and to identify their similarities and differences, information from various books and other works on the grammar of the two languages have been used. To discuss the morpho-syntactic features of each constituent and their structural relation in the noun phrase of Wolof, some examples are given by the researcher who is a Wolof native speaker while the others have been gathered from Pathe Diagne (1991)'s Grammaire De Wolof Moderne, and from Faye's (2012) Grammaire Didactique du Wolof Parlé .The data used in the English noun phrase in the study is mainly collected from Thomas E. Paye (1997)'s Describing Morphosyntax: A Guide for Field Linguistics and Michael Swan's (1996) Practical English Usage. The data of both languages are described and analysed through the contrastive method.

\section{Analysis and discussions}

As mentioned above, the analysis and discussion of this study focuses on an examination of three elements of Wolof and English noun phrases. This includes the noun head and two of its dependents namely, the definite article and the possessive determiner.

\subsection{Nouns}

A noun functioning as the head of a noun phrase has not been given an exact definition in the literature. Many linguists identify a noun on the basis of some criteria that distinguish it from the other elements of the phrase. For instance, nouns can be recognized by the fact that they occur after definite articles and by the fact that they are inflected to show number distinction. These characteristics can help to identify nouns in some languages like English where nouns are preceded by the definite article and show contrast in form between singular and plural (e.g. the book; one book versus two books). However, these criteria are not sufficient to recognize nouns in other languages such as Wolof. In Wolof, the noun head is not preceded by the definite article. It is also invariable and does not take any inflection in the plural form. To better understand the noun head and its relations to the other elements of the noun phrase, both in English and Wolof, we discuss the main features of noun system in both languages.

\subsubsection{Noun classes}

The noun class system typically involves the presence of classifiers (special operators that are used in some or all noun phrases directly expressing the class of the noun). The use of noun classes is one of the major distinguishing features between Wolof and English. English does not use noun classes in its grammatical system of noun classification while Wolof nouns are determined by a set of noun classes. As maintained (Laughlin 1997: 1), this is because Wolof is a member of the North Atlantic sub-group of the Atlantic family of Niger-Congo languages; and this is characterized by some of the most extensive and morph phonologically elaborate noun class systems found in natural languages.

There are ten noun classes in Wolof, eight singular and two plural. These class markers appear in the form of a consonant on nominal dependents such as determiners and relative particles. In this study, noun classes will be referred to as consonants that appear on the determiners of the noun. A set of Wolof noun classes is listed in (1).

1. Singular classes $: k-/ b-/ g-/ j-/ l-/ m-/ s-/ w-$

Plural classes: $\tilde{n}-/ y$ -

Yet, one thing is worth noting with the use of these noun classes. The $b$-class tends to be the default class and is by far the most common one in present-day spoken Wolof. It is the class of loan words from languages such as French and English. Researchers agree that the expansion of this class is also highly due to the fact that Wolof is daily used by non-native speakers and this contributes to the simplification of the language.

\subsubsection{Number marking}


Number is another grammatical feature of the noun and to which the principle of agreement may apply. It is a property of a noun that indicates whether the noun names one person or one thing or more. Wolof uses noun classes to form the singular and plural form of nouns while English mostly marks number using a suffix. Wolof nouns are invariable and there are no morphological suffixes to indicate the plural number of nouns. The distinction in number is marked on the noun classes listed above. As noted in (1), classes are either singular or plural, meaning that a change in number involves a change in class. Singular and plural forms are distinguishable unless they occur in a noun phrase that includes a dependent that agrees with the noun. Examples of singular and plural forms of nouns, followed by their definite articles are given below in (2). All nouns in left side are singular and their plural form on the right side has two consonant classes: $-y$ and $-\tilde{n}$.

It is good to mention that the $\tilde{n}$ - class forms the plural form of the $k$ - class exclusively reserved to the group of human beings. All nouns determined by the other noun classes can make their plural form with the $y$-class.

2. $\boldsymbol{b}$ - tank $b$ i (the leg)

g- garab gi (the tree)

$\boldsymbol{k i}$ - nit $k i$ (the person)

j-jigéen ji (the women) y- tank yi (the legs)

$\mathbf{y}$ - garàb yi (the trees)

$\tilde{\mathbf{n}}-$ nit $\tilde{n} i$ (the persons)

$\tilde{\boldsymbol{n}}$-jigéen ñi (the women)

Contrary to Wolof, in English, the expression of number is closely attached to the substantive itself. Singular nouns are grammatically distinguished from plural nouns. Number is usually expressed in the form of sibilant at the end of the word or through a vowel alternation within the noun as in (3) and (4).

$\begin{array}{lll}\begin{array}{l}\text { 3. Singular } \\ \text { Boy }\end{array} & \text { plural } & \\ \text { Man } & \text { boys } & \\ \text { men } & \text { (Salim, 1991: 13) }\end{array}$

\subsubsection{Gender marking}

As in the expression of number, Wolof nouns take no morphological features indicating their gender. Generally, to make the distinction between the two genders, Wolof adds the terms 'góor' (male) and 'jigéen' (female) to the neutral noun. Thus Wolof says:
ab xale bu góor $=($ a male child $)$
a boy
ab xale bu jigéen $=($ a female child $)$
a girl
(Faye, 2012: 15)

In English nouns, gender is generally a covert category shown by the occurrence of relevant pronouns: (the boy... he); (the girl ... she). Like Wolof, in English there is nothing about the morphological form of the nouns boy and girl which would indicate that they are masculine or feminine.

However, gender may be expressed overtly on the English noun in a number of limited ways. These include:

- Derivation suffixes, such as the feminine suffixes -ine (hero / heroine), -rix (aviator / aviatrix), and -ette (suffragist / suffragette) or the common gender suffixes -er (backer), -ist (artist), -ian (librarian), -ster (pranskster), and -ard (drunkard);

- Compounds, such as lady-, woman-, girl, female, -woman or boy-, male-, gentleman-, -man;

- Separate forms for masculine, feminine, and common genders, such as boy / girl

The comparison of the three mentioned notions (noun classes, number and gender marking) in English and Wolof shows that each language characterizes noun in a distinct way. Noun classes are typical to Wolof while number marking is only used in English. However, similarities exist between the two languages. Nouns take no morphological features showing gender (except in some rare cases in English).

\subsection{Determiners}

Determiners specify the substantive to which they are subordinated as well as the entire noun phrase. Determiners are generally classified into two main categories:

The first category of determiners help to identify things, to say whether they are known or unknown to the listener, which thing(s) the speaker is talking about, whether the speaker is thinking of particular examples or speaking in general, etc. These include articles, possessives and demonstratives. Most of the second type of determiners are quantifiers. They say how much or how many we are talking about. This classification is not exhaustive because there are some determiners that do not fit in category 1 and 2 (Swan, 1995: 148-149).

What has been observed is the determiner can occupy different positions in the noun phrase in both English and Wolof. For instance, in (5) the English demonstrative this pre-modifies the noun head house while its Wolof counterpart gii occupies the final position of the corresponding noun phrase.
5.
English
Wolof
This house
kër gii 
As mentioned earlier, the English and Wolof noun phrases compared in this study include two determiners: the definite article and the possessive. Both determiners fit the first category. In English, they form mutually exclusive terms, meaning that the occurrence of any given determiner excludes the presence of another in the same noun phrase. Contrary to English, a Wolof noun phrase accepts more than one of these determiners (e.g., possessive and article; or possessive and demonstrative). This difference is further explained below.

\subsubsection{Definite articles}

Definite articles are used when we refer to things that are known both to the speaker and the listener. In English the definite article is expressed by 'the' placed before the noun head while in Wolof the definite article is formed with the noun class combined with vowels such as " $i$ ", or "- $a$ " and post-modify the noun. The choice between the two vowels " $-i$ or $-a$ " depends on the closeness or remoteness of the referred term. If this item is closed to the person who speaks (both in space and time), the definite article will be composed of the noun class and " $i$ ". But, if the related term is far from the speaker, the definite article is composed of the noun class and the vowel " $a$ ". The two forms of definite articles are presented below in (6).

6.

\section{$\underline{\text { Class }}$}

$k$ -

$b$ -

g-

$j-$

$l-$

$m-$

$S-$

$w-$
Wolof definite articles (noun class $+-i$ or $-a$ )

singular
nit ki / ka
xale bi / ba
kër gi / ga
jigéen ji / ja
ndab li / la
muus mi / ma
safara si / sa
fas wi / wa

plural
nit ñi / na
xale yi / ya
kër yi / ya
jigéen ñi / ña
ndab yi / ya
muus yi / ya
safara yi / ya
fas yi / ya

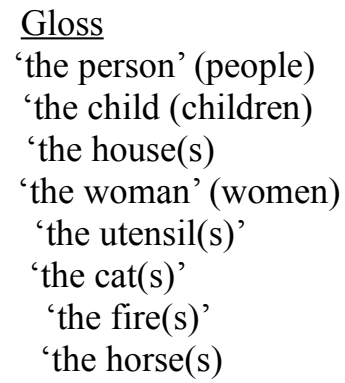

It has been observed that the formation of the definite article and its position towards the noun head differ from English to Wolof. Yet, there is a situation in which the two languages follow the same rule. In many grammatical cases the definite article is omitted in English. For instance, when we are talking about people or things in general we do not usually use the definite article with uncountable or plural nouns as in (7).
7. $\quad$ Life is complicated
not *the life is complicated
She loves horses
not * she loves the horses

This use of definite articles is the same in Wolof where the noun can stand without an article. In (8), both the Wolof nouns aduna (life) and fas (horses) do not require the definite article.
8. $\quad$ Wolof
Aduna dafa doy waar
Gloss
Dafa bëgg fas
life is complicated
he/ she/ it loves horses

\subsubsection{Possessive determiners}

Wolof possessive determiners are classified into two categories: singular possessives as in (9) and plural possessives, listed in (10) and (11).

\begin{tabular}{|c|c|}
\hline \multicolumn{2}{|c|}{ Wolof Singular possessives } \\
\hline Wolof & English \\
\hline suma & my \\
\hline sa & your \\
\hline -am & his, her, its \\
\hline sunu & our \\
\hline séen & your \\
\hline seen & their \\
\hline
\end{tabular}

The first possessive determiner suma has another variant sama; and sunu (our) is also interchangeably used with its equivalent form suñu. It is also worth noting that in spoken Wolof, people do not make a distinction between séen (your) and seen (their).

\section{- Wolof Plural possessives}

The Wolof plural mark is $-i$ (Faye Ebd: 43). In their plural forms, the above listed singular possessives become bound with the plural morpheme $-i$ as in (10). But, when a possessive ends with a vowel, the contact of this vowel and the plural morpheme $-i$ gives the morpheme $-y$ as it can be seen in (11). What is worth noting with these plural possessives is, the addition of particle $-i$ does not imply the $3^{\text {rd }}$ person singular form -am which a bound morpheme suffixed to the noun.
10. Wolof
English 
séeni doom

seeni doom your children

their children

11.

Wolof
samay (sumay) xarit
say xarit
sunuy (suñuy) xarit

English

my friends

your friends

our friends

The English possessive determiners are: my, your, his, her, its, our and their. Like their Wolof counterparts, English possessives are placed before the noun head (except with the $3^{\text {rd }}$ singular possessive morpheme -am suffixed to the noun). However, contrary to Wolof, English possessives are invariable and do not agree in number with the noun they accompany. This is shown in (12).

12. $\quad$ English: My book/ My books

There exists a variation in English with possessives his, her and its. This variation is often referred to as a distinction of gender. The reference in this case is the sex of the possessor, a feature not expressed by the Wolof possessive determiners. For instance, the Wolof noun phrase at-am has three equivalent forms in English: his age / her age/ its age.

\subsection{Types of Noun Phrases in English and Wolof}

The noun is the main element of a noun phrase to distinguish it from other phrases. Both in English and Wolof, a single noun can function as a noun phrase. In (13), each of the three English noun life, man, children; and their Wolof equivalents aduna, góo rand xale can fully play a role of a noun phrase.

$$
\text { English: life, man, child } \quad \text { Wolof: aduna, góor, xale }
$$

Yet, a noun phrase can take an unlimited number of constituents including (determiners, numerals, genitives, adjectives etc.). From there, we can have a two-element noun phrase, a three-element noun phrase or more. As already stated, the investigation of the similarities and differences between the English and Wolof noun phrases only involve the possible combination among three elements: the noun, the definite article and the possessive determiner.

Recall that definite articles, possessives and demonstratives are classified in Category 1 determiners. In his book 'Practical English Usage', Swan calls them Group A determiners and says that in English, we cannot put two determiners of this group together. We can say: the house, my house or this house, but not the my house, the this house, this my house or my this house(Swan 1996: 148). So, in this study, only two types of noun phrase are possible in English. The first one is a one-element noun phrase (composed of a single noun). The second type is a two-element noun phrase (formed with a definite article + noun head or a possessive determiner + a noun head). The combination of both definite article and possessives is not accepted.

Contrary to English, in Wolof the noun head can be either pre-modified or post-modified by the two determiners in question. For instance, the definite article is placed after the noun while the possessive determiner (except the suffix -am) occupy the initial position in the noun phrase. The other difference is Wolof noun head accepts both of the two determiners. It can be preceded by the possessive and followed by the definite article in a same noun phrase, creating then a three-element noun phrase. Faye (Ebd. 42) explains that even with the presence of a possessive determiner, a noun can take its definite article to indicate specification and localization in a Wolof noun phrase. For him, this is because the Wolof possessive determiner is used in an indefinite context. For instance, the noun phrase $\boldsymbol{s} \boldsymbol{a}$ fas (your horse) only refers to a horse that belongs to you while sa fas wi expresses a specific and definite horse.
Wolof:
Sa fas
Sa fas wi
English
your horse (unspecific horse)
your horse (specific horse)

\section{Conclusion}

Studying the noun phrase can be as complex as one wishes. That is why I have limited my analysis to the simple noun phrase including three main elements: the noun head, the definite article and the possessive determiner. After analysis, it has been revealed that the English and Wolof noun phrases present more differences than similarities.

The main difference between the two languages is, the use of noun classes is typical to Wolof. Wolof nouns are determined by a set of noun classes that generally appear on the determiners. Another difference is Wolof nouns take no morphological marks indicating number while in English singular nouns are morphologically distinguished from plural nouns. However, there is a similarity between the two languages with the expression of gender. With rare exceptions, English nouns do not take a mark distinguishing masculine or feminine gender, a feature which also characterizes their Wolof counterparts.

With the use of possessives, the analysis has shown that the English noun phrase and the Wolof noun phrase also present similarities and differences. Functioning as a noun head, the noun is pre-modified by possessive 
determiners in both languages, with the exception of the bound possessive -am, suffixed to the noun in Wolof. The difference between the two languages is in Wolof, possessive determiners agree in number with their heads while English possessives are invariable and do not agree in number and gender except with a variation between his / her / and its, a feature that is not expressed by Wolof possessives.

One of the most important differences between the two types of noun phrases occurs in the use of definite articles. Structurally, in English, the definite article 'the' occupies the initial position of the noun phrase while in Wolof, it comes after the noun. The morphology of Wolof definite articles is also one of the main distinctive features between the two languages. Wolof definite articles are made of the noun class of the head and agree in number and location (proximity or remoteness) with the latter while English only has one form 'the'.

Finally, another major feature that distinguishes the two languages is, in English, a noun phrase cannot contain both the definite article and the possessive determiner at the same time while in Wolof, the presence of both determiners is accepted.

The comparison of the English and Wolof noun phrases confirms the hypothesis set earlier in the study because it reveals more differences than similarities. Differences have been noted at both the morphological and syntactic levels of the noun phrase's constituents. Yet, I believe that further research investigating other phrases like the adverbial phrase, the verb phrase or even the whole sentence would show to what extent English and Wolof grammar are similar or different.

\section{References}

Al Faki, I. (2014). A Contrastive Study in Sentence Construction between English and Nubian Languages: American International Journal of Contemporary Research, Vol. 4, No. 5.

Diagne, S. (2013). The Morphological and Syntactic Analysis of Possessives in English and Wolof: Cheikh Anta Diop University, Dakar.

Faye, S. (2012). Grammaire Didactique du Wolof Parlé: Les Editions Du Livre Universel, E.L.U

Laurel, J. B. (1984). The Structure of Modern English: A linguistic introduction: University of British Columbia.

Liu, Y. (2014). A Comparative Study of English Tense and French Tense: Theory and Practice in Language Studies, Vol. 4, No. 11, pp. 2314-2321.

Mbaye, D. (2014). A Contrastive Study of Affixation in English and Wolof: Cheikh Anta Diop University.

Mc Laughlin, F. (1997). Noun Classification in Wolof: When Affixes Are Not Renewed: Studies in African Linguistics, Vol. 26, No.1.

Ndione, A. (2013). Contribution à étude de la différence entre la réduplication et la répétition en français et en Wolof: Thèse de Doctorat, Université François-Rabelais de Tours.

Payne, T. E. (1997). Describing Morpho-syntax: A Guide for Field Linguists: Cambridge University Press.

Salim, A. (1991). French and English Noun Phrases: Southern Illinois University Carbondale, Open SIUC.

Salim, J. A. (2013). A Contrastive Study of English-Arabic Noun Morphology: International Journal of English Linguistics; Vol. 3, No. 3.

Swan, M. (1996). Practical English Usage (Second Edition): Oxford University Press. 